\title{
CASP3 gene single-nucleotide polymorphism (rs72689236) and Kawasaki disease in Taiwanese children
}

\author{
Ho-Chang Kuo ${ }^{1,2}$, Hong-Ren Yu, ${ }^{1,2}$, Suh-Hang Hank Juo ${ }^{3,4}$, Kuender D Yang ${ }^{1,2}$, Yu-Shiuan Wang ${ }^{3}$, \\ Chi-Di Liang ${ }^{5}$, Wei-Chiao Chen ${ }^{3}$, Wei-Pin Chang ${ }^{6}$, Chien-Fu Huang ${ }^{5}$, Chiu-Ping Lee ${ }^{1}$, Li-Yan Lin ${ }^{1}$, \\ Yu-Chen Liu ${ }^{1}$, Yuh-Cherng Guo ${ }^{7}$, Chien-Chih $\mathrm{Chiu}^{8}$ and Wei-Chiao Chang 3 3,9,10
}

Kawasaki disease (KD) is characterized by systemic vasculitis of unknown etiology. A study from Japan reported that G to A substitution of a single-nucleotide polymorphism (SNP) located in the 5'-untranslated region of caspase 3 (CASP3) (rs72689236), which was associated with nuclear factor of activated T cell-mediated T-cell activation, is responsible for susceptibility to KD. This study was conducted to investigate whether the polymorphism of CASP3 is responsible for susceptibility and coronary artery lesion (CAL) formation in KD in the Taiwanese population. A total of 1092 subjects (341 KD patients and 751 controls) were investigated to identify an SNP of rs72689236 using Invader assays (Third Wave Technologies). Our data provided a borderline significant association between the genotypes and allele frequency of rs72689236 in control subjects and KD patients $(\boldsymbol{P}=\mathbf{0 . 0 5 3 5}$ under the dominant model; $\boldsymbol{P}=\mathbf{0 . 0 5 7 5}$ under the allelic model). The $\mathrm{A}$ allele of rs72689236 in KD patients and in patients with CAL and intravenous immunoglobulin resistance was seen in a higher frequency. Importantly, a significant association was obtained between rs72689236 and KD patients with aneurysm formation $(\boldsymbol{P}=\mathbf{0 . 0 0 9}$, under the recessive model). The A allele of rs72689236 is very likely to be a risk allele in the development of aneurysm in patients with KD.

Journal of Human Genetics (2011) 56, 161-165; doi:10.1038/jhg.2010.154; published online 16 December 2010

Keywords: aneurysm; CASP3; coronary artery lesions; intravenous immunoglobulin; kawasaki disease

\section{INTRODUCTION}

Kawasaki disease (KD) is characterized by acute febrile systemic vasculitis and was first reported by Kawasaki et al. in $1967 ;^{1}$ however, its etiology has been unknown till now. In developed countries, KD is the leading cause of acquired heart disease in children. ${ }^{2,3} \mathrm{KD}$ occurs worldwide and mainly affects children less than 5 years of age, especially in Asian countries; the disease has an incidence of 69-213 cases per 100000 children aged less than 5 years in Japan, Korea and Taiwan. ${ }^{4-6}$ The clinical characteristics of KD include prolonged fever for more than 5 days, diffuse oral mucosal inflammation, bilateral non-purulent conjunctivitis, dysmorphous skin rashes, indurations over the hands and feet and cervical lymphadenopathy. ${ }^{7}$ The most serious complication of KD is coronary artery lesions (CALs), including myocardial infarction, coronary artery fistula, ${ }^{8}$ coronary artery dilatation and coronary artery aneurysm. ${ }^{9,10}$ Studies conducted have either failed to identify certain pathogens responsible for KD or have reported discrepant results. ${ }^{11-13}$ Therefore, the genetic background may have a more important role in the pathogenesis of KD.

Recently, several studies showed the associations between genetic polymorphism and the risk of KD. ${ }^{14-16}$ A single-nucleotide polymorphism (SNP) (rs28493229) was found in the inositol 1, 4, 5trisphosphate 3-kinase C (ITPKC) gene, which is an important mediator in the activation of $\mathrm{T}$ lymphocytes. The polymorphism of ITPKC that influences ITPKC expression by altering the RNA splicing efficiency is responsible for the susceptibility to KD and development of coronary artery abnormalities. ${ }^{14} \mathrm{~A}$ report from the same group further indicated that a common variant in the $5^{\prime}$-untranslated region of caspase 3 (CASP3) effects the binding of nuclear factor of activated $\mathrm{T}$ cells and contributes to the susceptibility to $\mathrm{KD}$ but not to CAL formation in both Japanese and US subjects of European ancestry. ${ }^{15}$

\footnotetext{
${ }^{1}$ Division of Allergy, Immunology and Rheumatology, Department of Pediatrics, Chang-Gung Memorial Hospital-Kaohsiung Medical Center, Kaohsiung, Taiwan; ${ }^{2}$ Graduate Institute of Clinical Medical Science, Chang Gung University College of Medicine, Kaohsiung, Taiwan; ${ }^{3}$ Department of Medical Genetics, College of Medicine, Kaohsiung Medical University, Kaohsiung, Taiwan; ${ }^{4}$ Department of Medical Research, Kaohsiung, Taiwan; ${ }^{5}$ Division of Cardiology, Department of Pediatrics, Chang Gung Memorial Hospital-Kaohsiung Medical Center, Kaohsiung, Taiwan; ${ }^{6}$ Department of Healthcare Management, Yuanpei University, HsinChu, Taiwan; 7 Department of Neurology, Kaohsiung Municipal Hsiao-Kang Hospital, Kaohsiung Medical University, Kaohsiung, Taiwan; ${ }^{8}$ Department of Biotechnology, Kaohsiung Medical University, Kaohsiung, Taiwan; ${ }^{9}$ Cancer Center, Kaohsiung Medical University Hospital, Kaohsiung, Taiwan and ${ }^{10}$ Center of Excellence for Environmental Medicine, Kaohsiung Medical University, Kaohsiung, Taiwan

Correspondence: Dr W-C Chang, Department of Medical Genetics, College of Medicine, Kaohsiung Medical University, 100 TzYou First Road, Kaohsiung City, Taiwan 807, Taiwan. E-mail: wcc@kmu.edu.tw
}

Received 22 August 2010; revised 2 November 2010; accepted 6 November 2010; published online 16 December 2010 
CASP3 is one of the effector caspases that has an important role in the execution phase of apoptosis. Apoptosis is a programmed cell death that is regulated by caspases, a family of cysteine-dependent proteases. ${ }^{17,18}$ According to its functions, caspases are divided into initiator caspases and effector caspases. ${ }^{17-19}$ External signals from receptors trigger initiator caspases (caspases-2, 8, 9 and 10), which results in the activation of downstream effector caspases (caspases-3, 6 and 7). ${ }^{17-19}$ Mutations in CASP3 have been found in gastric cancer, non-small-cell lung cancer and squamous cell carcinoma of the head and neck. ${ }^{20-22}$

We hypothesized that SNP rs72689236 of CASP3 may be involved in susceptibility to $\mathrm{KD}$, CAL formation, development of aneurysm and intravenous immunoglobulin (IVIG) treatment response in Taiwanese children. To test this hypothesis, we conducted a case-control study of 341 patients with KD and 751 controls in Taiwan.

\section{MATERIALS AND METHODS}

\section{Patients}

All patients studied were children who fulfilled the diagnostic criteria for KD and were admitted for IVIG treatment at Chang Gung Memorial HospitalKaohsiung Medical Center, from 2001 and 2009. All patients were treated with a single high dose of IVIG $(2 \mathrm{~g} / \mathrm{kg})$ over a $12 \mathrm{~h}$ period. ${ }^{7,10,23}$ This study was approved by the Institutional Review Board of Chang Gung Memorial Hospital. Blood samples were collected after informed consent was obtained from parents or guardians. We excluded patients who did not fit the diagnostic criteria for $\mathrm{KD}$, and those who had fever for less than 5 days. Echocardiography was performed at acute stage during admission, 6-8 weeks after disease onset, followed by 6 months and then 1 year after disease onset. Follow-up echocardiography was performed according to the severity of coronary artery involvement. CAL was defined by the internal diameter of the coronary artery being greater than $3 \mathrm{~mm}$ ( $4 \mathrm{~mm}$, if the subject was over the age of 5 years) or the internal diameter of a segment being at least 1.5 times larger than that of an adjacent segment, as observed in the echocardiogram. ${ }^{7,24} \mathrm{KD}$ patients with coronary artery ectasia or dilatation, which disappeared within the initial 8 weeks after the onset of illness, were defined as having transient ectasia and not CAL. ${ }^{9}$ In addition, coronary arteries were classified on the basis of the presence or absence of aneurysms according to criteria from the JCS Joint Working Group. Aneurysms (including medium and giant aneurysms) were defined by the internal diameter of the coronary artery being greater than $4 \mathrm{~mm}$ or, in children over the age of 5 years, the internal diameter of a segment being at least 1.5 times that of an adjacent segment. ${ }^{25}$

IVIG treatment responsiveness was defined as defervescence $48 \mathrm{~h}$ after the completion of IVIG treatment and no fever (temperature, $>38^{\circ} \mathrm{C}$ ) recurrence for at least 7 days after the initial IVIG treatment, with marked improvement of inflammatory signs. ${ }^{7,26,27}$ Patients with IVIG resistance received another dose of IVIG $(1-2 \mathrm{~g} / \mathrm{kg})$ or other anti-inflammatory regiments.

\section{DNA extraction}

Blood cells were subjected to DNA extraction by treating them first with $0.5 \%$ SDS lysis buffer and then with protease $\mathrm{K}(1 \mathrm{mg} / \mathrm{ml})$ for digestion of nuclear protein for $4 \mathrm{~h}$ at $60^{\circ} \mathrm{C}$. Total DNA was harvested by using the Gentra extraction kit (Corte Del Nogal, Carlsbad, CA, USA), followed by $70 \%$ alcohol precipitation as our previous report. ${ }^{28}$

\section{Genotyping}

Genotyping was carried out using Invader assays (Third Wave Technologies, Japan). Briefly, PCR was performed to amplify a PCR product of CASP3 that contained SNP rs72689236. The thermal cycle conditions were as follows: denaturing at $95^{\circ} \mathrm{C}$ for $10 \mathrm{~min}$, followed by 35 cycles of denaturing at $92{ }^{\circ} \mathrm{C}$ for $15 \mathrm{~s}$ and annealing and extension at $58.5^{\circ} \mathrm{C}$ for $1 \mathrm{~min}$. The sequences of primers used are F: 5'-TCCTAGCGGATGGGTGCTAT-3'; R: 5'-TGGCAAAACAAACAC TCCGCC- $3^{\prime}$. After PCR, 173 bp PCR products were checked by running a gel electrophoresis (Figure 1). Fluorescence was measured and analyzed using Invader assays.

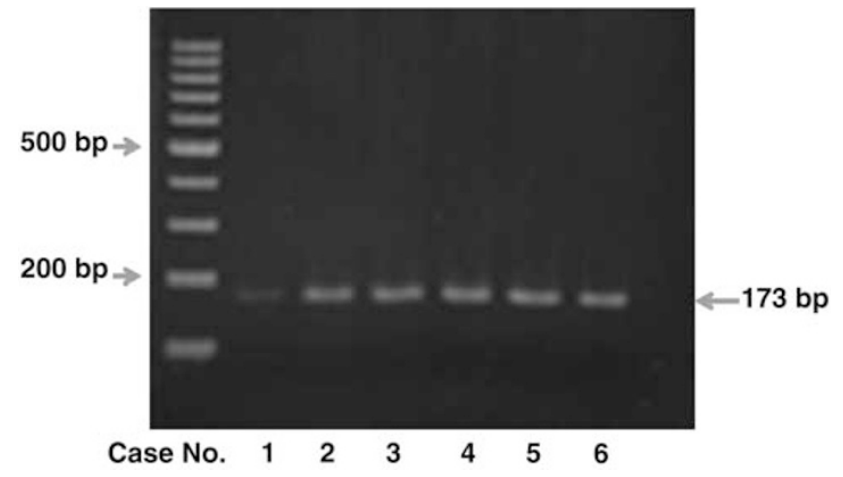

Figure $1173 \mathrm{bp}$ of CAPS3 PCR product was determined by gel electrophoresis. A full color version of this figure is available at the Journal of Human Genetics journal online.

Table 1 Basal characteristics of patients with KD and of normal controls

\begin{tabular}{lcc}
\hline Characteristics & Patients with KD & Normal Control \\
\hline No. of subjects & 341 & 751 \\
Gender: male, no. (\%) & $226(66.3 \%)$ & $445(59.3 \%)$ \\
Age (years) & $1.6 \pm 1.4$ & $38.0 \pm 19.1$ \\
Range & $3.5-144$ (months) & $16-87$ (years) \\
CALs & $35(10.3 \%)$ & \\
Aneurysm formation & $14(4.1 \%)$ & \\
IVIG resistant & $43(12.6 \%)$ &
\end{tabular}

Abbreviations: CAL, coronary artery lesion; IVIG, intravenous immunoglobulin; KD, Kawasaki disease.

\section{Statistical analysis}

The Hardy-Weinberg equilibrium was first checked. The statistical differences between cases and controls in genotype and allele frequency were assessed by the $\chi^{2}$-test. The statistical differences in the genotype and allele frequency of $\mathrm{KD}$ patients with and without CAL formation, aneurysm formation, as well as of patients responding to IVIG and those showing resistance, were assessed using the $\chi^{2}$-test. SAS 9.1 for Windows (SAS Inc., Cary, NC, USA) was used for data analysis.

\section{RESULTS}

Borderline significant association of SNP rs72689236 of CASP3 with susceptibility to $\mathrm{KD}$

In this study, a total of $341 \mathrm{KD}$ patients and 751 controls were included. Table 1 shows the characteristics of the subjects. The prevalence of $\mathrm{KD}$ is less than $1 / 1000$ children in the Taiwanese population. Therefore, we assumed that there was no KD case in the control group. In all, $10.3 \%$ of KD patients were observed with CAL formation 8 weeks after disease onset, and $12.6 \%$ were IVIG resistant. The CAL formation rate was higher in KD patients with IVIG resistance than in those who were responsive to IVIG (12/43 versus $23 / 298, P<0.001$ ). A total of $12 \mathrm{KD}$ patients with $\mathrm{CAL}$ formation $(12 / 35,34.3 \%)$ were included in those showing unfavorable response to initial IVIG treatment, and 23 patients were included who had CAL $(23 / 35,65.7 \%)$ and responded well to initial IVIG treatment.

Different alleles of rs72689236 have been reported to influence the CASP3 gene expression and further effect KD susceptibility in Japanese and European American subjects. ${ }^{15}$ In this study, as shown in Table 2, the difference in rs72689236 allele frequencies between KD patients and controls was borderline significant $(P=0.0535$, dominant model, Table 2). The major $\mathrm{G}$ allele of rs72689236 was overrepresented in controls than in $\mathrm{KD}$ patients (48 versus $42 \%$ ). 
Table 2 Genotype frequencies for CASP3 SNP and KD susceptibility

\begin{tabular}{|c|c|c|c|c|c|c|c|c|c|c|}
\hline & Genotype & $\begin{array}{l}\text { Case (\%) } \\
(\mathrm{n}=341)\end{array}$ & $\begin{array}{c}\text { Control subjects } \\
(\%)(\mathrm{n}=751)\end{array}$ & Allele & $\begin{array}{l}\text { Case (\%) } \\
(n=341)\end{array}$ & $\begin{array}{c}\text { Control subjects } \\
(\%)(n=751)\end{array}$ & $\begin{array}{c}\text { Genotype } \\
\text { P-value }\end{array}$ & $\begin{array}{c}\text { Dominant } \\
\text { P-value }\end{array}$ & $\begin{array}{c}\text { Recessive } \\
\text { P-value }\end{array}$ & $\begin{array}{l}\text { Allelic } \\
\text { P-value }\end{array}$ \\
\hline \multirow[t]{3}{*}{ rs72689236 } & AA & $35(11)$ & $66(10)$ & $A$ & 211 (35) & $421(31)$ & 0.145 & 0.0535 & 0.340 & 0.0575 \\
\hline & $A G$ & $141(47)$ & $289(42)$ & G & 395 (65) & 959 (69) & & & & \\
\hline & GG & $127(42)$ & $335(48)$ & & & & & & & \\
\hline
\end{tabular}

Abbreviations: CASP3, caspase 3; KD, Kawasaki disease; SNP, single-nucleotide polymorphism.

Table 3 Genotyping and allele frequency of CASP3 SNP in patients with CAL and without CAL

\begin{tabular}{|c|c|c|c|c|c|c|c|c|c|c|}
\hline & Genotype & $\begin{array}{l}C A L(\%) \\
(n=35)\end{array}$ & $\begin{array}{l}\text { Without } \\
(\%)(n=306)\end{array}$ & Allele & $\begin{array}{c}C A L \\
(\%)(n=35)\end{array}$ & $\begin{array}{l}\text { Without } \\
\text { (\%) }(n=306)\end{array}$ & $\begin{array}{l}\text { Genotype } \\
\text { P-value }\end{array}$ & $\begin{array}{c}\text { Dominant } \\
\text { P-value }\end{array}$ & $\begin{array}{c}\text { Recessive } \\
\text { P-value }\end{array}$ & $\begin{array}{l}\text { Allelic } \\
\mathrm{P} \text {-value }\end{array}$ \\
\hline \multirow[t]{3}{*}{ rs72689236 } & $\mathrm{AA}$ & $6(21)$ & $29(11)$ & A & $26(45)$ & $185(34)$ & 0.209 & 0.228 & 0.193 & 0.101 \\
\hline & $A G$ & $14(48)$ & $127(47)$ & $\mathrm{G}$ & 32 (55) & 359 (66) & & & & \\
\hline & GG & $9(31)$ & $116(42)$ & & & & & & & \\
\hline
\end{tabular}

Abbreviations: CAL, coronary artery lesion; CASP3, caspase 3; SNP, single-nucleotide polymorphism.

Table 4 Genotyping and allele frequency of CASP3 SNP in patients with resistant and responsive to IVIG treatment

\begin{tabular}{|c|c|c|c|c|c|c|c|c|c|c|}
\hline & Genotype & $\begin{array}{l}\text { Resistant } \\
(\%)(n=43)\end{array}$ & $\begin{array}{l}\text { Responsive } \\
(\%)(n=298)\end{array}$ & Allele & $\begin{array}{l}\text { Resistant } \\
(\%)(n=43)\end{array}$ & $\begin{array}{l}\text { Responsive } \\
(\%)(n=298)\end{array}$ & $\begin{array}{l}\text { Genotype } \\
\text { P-value }\end{array}$ & $\begin{array}{c}\text { Dominant } \\
\text { P-value }\end{array}$ & $\begin{array}{c}\text { Recessive } \\
\text { P-value }\end{array}$ & $\begin{array}{l}\text { Allelic } \\
\text { P-value }\end{array}$ \\
\hline \multirow[t]{3}{*}{ rs72689236 } & $A A$ & $6(15)$ & $29(11)$ & $A$ & $30(38)$ & $181(34)$ & 0.764 & 0.792 & 0.464 & 0.589 \\
\hline & $A G$ & $18(45)$ & $123(47)$ & G & $50(62)$ & 345 (66) & & & & \\
\hline & GG & $16(40)$ & 111 (42) & & & & & & & \\
\hline
\end{tabular}

Abbreviations: CASP3, caspase 3; IVIG, intravenous immunoglobulin; SNP, single-nucleotide polymorphism.

Table 5 Genotyping and allele frequency of CASP3 SNP in patients with transient ectasia

\begin{tabular}{|c|c|c|c|c|c|c|c|c|c|c|}
\hline & Genotype & $\begin{array}{c}\text { Transient ectasia } \\
\text { (\%) }(\mathrm{n}=86)\end{array}$ & $\begin{array}{c}\text { Without } \\
(\%)(n=255)\end{array}$ & Allele & $\begin{array}{l}\text { Transient ectasia } \\
\text { (\%) }(\mathrm{n}=86)\end{array}$ & $\begin{array}{l}\text { Without (\%) } \\
(\mathrm{n}=255)\end{array}$ & $\begin{array}{l}\text { Genotype } \\
\text { P-value }\end{array}$ & $\begin{array}{l}\text { Dominant } \\
\text { P-value }\end{array}$ & $\begin{array}{c}\text { Recessive } \\
\text { P-value }\end{array}$ & $\begin{array}{l}\text { Allelic } \\
\text { P-value }\end{array}$ \\
\hline \multirow[t]{3}{*}{ rs72689236 } & $A A$ & $6(8)$ & $29(11)$ & $A$ & $48(33)$ & $185(34)$ & 0.799 & 0.881 & 0.561 & 0.879 \\
\hline & $A G$ & $36(50)$ & $127(47)$ & G & $96(67)$ & 359 (66) & & & & \\
\hline & GG & $30(42)$ & $116(42)$ & & & & & & & \\
\hline
\end{tabular}

Abbreviations: $C A S P 3$, caspase 3; SNP, single-nucleotide polymorphism.

No significant association of SNP rs72689236 of CASP3 with CAL formation and IVIG treatment response in KD patients

A total of $341 \mathrm{KD}$ patients were included in this study, of whom 35 (10.3\%) had CAL formation and $43(12.6 \%)$ were resistant to initial IVIG treatment (Table 1). We further evaluated the relationship between rs72689236 and the risk of CAL formation or IVIG resistance. As shown in Table 3 and Table 4 , the frequency of the AA genotype was higher in patients with CAL formation (21 versus $11 \%$ ) or IVIG resistance ( 15 versus $11 \%$ ). The genotype or allele frequency of rs72689236, however, was not statistically associated with CAL formation (Table 3 ) or IVIG resistance (Table 4).

SNP rs72689236 of CASP3 was associated with KD patients with aneurysm formation

To further identify the role of rs72689236 of CASP3 in the pathogenesis of CAL in KD patients, we performed a subset analysis in which cases reported having transient ectasia $(86 / 341,25.2 \%)$ or aneurysm formation (14/341, 4.1\%). Subset analysis between cases with transient ectasia and s72689236 did not yield any significant results (Table 5). Importantly, a significant association appears between rs72689236 and KD patients with aneurysm formation, with a $P$-value of 0.009 under the recessive model (Table 6).

\section{DISCUSSION}

$\mathrm{KD}$ is an immune-mediated disease. Several genes including ITPKC, CASP3 and MMP have been reported to be associated with susceptibility to KD and/or CAL formation in this disease. ${ }^{14,15,29}$ The results of most of the studies on genetics have been discrepant. ${ }^{14,16}$ The prevalence of KD in children younger than 5 years is higher in Asia than in Europe, indicating the possibility of complex genetic and ethnic association in KD between race and countries. Onouchi et al. first reported that altered CASP3 expression in immune effector cells influences susceptibility to KD. ${ }^{15}$ Our study was conducted to verify rs72689236 in the Taiwanese population with KD. Our data provided a 
Table 6 Genotyping and allele frequency of CASP3 SNP in patients with aneurysm

\begin{tabular}{|c|c|c|c|c|c|c|c|c|c|c|}
\hline & Genotype & $\begin{array}{c}\text { With (\%) } \\
(\mathrm{n}=14)\end{array}$ & $\begin{array}{c}\text { Without (\%) } \\
(\mathrm{n}=327)\end{array}$ & Allele & $\begin{array}{c}\text { With (\%) } \\
(n=14)\end{array}$ & $\begin{array}{c}\text { Without (\%) } \\
(\mathrm{n}=327)\end{array}$ & $\begin{array}{c}\text { Genotype } \\
\text { P-value }\end{array}$ & $\begin{array}{c}\text { Dominant } \\
\text { P-value }\end{array}$ & $\begin{array}{c}\text { Recessive } \\
\text { P-value }\end{array}$ & $\begin{array}{l}\text { Allelic } \\
\text { P-value }\end{array}$ \\
\hline \multirow[t]{2}{*}{ rs72689236 } & AA & $4(36)$ & $31(11)$ & A & $12(55)$ & 199 (34) & $0.031^{\mathrm{a}}$ & 0.316 & $0.009^{a}$ & $0.048^{a}$ \\
\hline & $\mathrm{GG}$ & $3(28)$ & $124(42)$ & & & & & & & \\
\hline
\end{tabular}

Abbreviations: $C A S P 3$, caspase 3; SNP, single-nucleotide polymorphism.

asignificant $(P<0.05)$ values are in bold.

borderline significance between rs72689236 and susceptibility to KD. The results indicate that the A allele carrier for rs72689236 seems to be related to the risk of KD in patients. Although rs72689236 did not have significant association with CAL formation or IVIG treatment response in KD patients, a significant association was found between CASP3 (rs72689236) and aneurysm formation of KD. The serious complication of KD was CAL formation, including myocardial infarction, coronary artery fistula, transient coronary artery ectasia (which disappears 8 weeks after disease onset), dilatation and aneurysm formation. Transient ectasia was not judged as CAL in this study, whereas aneurysm formation was included in the CAL group. Although aneurysm formation is the most dangerous complication of $\mathrm{KD}$ and needs long-term follow-up, we analyzed the association between $C A S P 3$ and aneurysm. Therefore, our results may imply that the genotype of CASP3 may be involved in the immunopathogenesis of CALs, which in turn contributes to the severity of KD.

The IVIG resistance rate was $12.6 \%$ in the present study, which is compatible with the results of our previous reports., ${ }^{723}$ Although various analyses were performed in this study, including subset analysis on subjects with CAL formation or IVIG resistance and analyses based on different cutoff points to redefine cases and controls, these approaches did not improve the statistical results. The population recruited into this study was relatively homogenous in terms of ethnicity and geographic location. Therefore, undetectable confounding factors could be minimized.

Kariyazono et al. ${ }^{30}$ and Breunis et al. ${ }^{31}$ reported that the vascular endothelial growth factor gene polymorphism was associated with susceptibility and CAL formation in $\mathrm{KD}$; however, it cannot be verified in the Taiwanese population. ${ }^{32}$ Burns et al. ${ }^{33}$ revealed that interleukin 4 has an important role in KD pathogenesis and disease susceptibility, but the results are different from the studies in the Taiwanese population..$^{34,35}$ The angiotensin-I-converting enzyme gene was reported to be associated with susceptibility to $\mathrm{KD}$ but not CAL formation in Taiwan, ${ }^{36}$ and it was shown to be associated with the formation of severe coronary artery stenosis and myocardial ischemia in the Japan population. ${ }^{37}$ In recent years, it has become clear that the intronic SNP (rs28493229) of ITPKC that is involved in the development of coronary artery abnormalities is an important factor in susceptibility to KD. ${ }^{14}$ However, the results obtained from the genetic association study between rs28493229 and KD susceptibility is inconsistent in the Taiwanese population. ${ }^{16,38}$ A larger sample size will be required to clarify this point. Taken together, the genetic studies of KD showed varied results in different studies from different populations, indicating that the genes responsible for KD varied with countries, ethnicity or area. Environmental factors may be considered as a crucial trigger in the susceptibility to $\mathrm{KD}$.

In conclusion, our study indicated that CASP3 (rs72689236) associated with susceptibility to $\mathrm{KD}$ and aneurysm formation in KD patients in the Taiwanese population. Importantly, the A allele of rs72689236 may predispose the risk of aneurysm formation in KD patients. We acknowledge that the current sample size was underpowered to exclude a small genetic effect of CASP3. The findings need to be confirmed in another population with a larger sample size. Further study on the relationship between genotype of CASP3 and downstream functional relevance during the pathogenesis of aneurysm formation would be helpful to understand the etiology of KD.

\section{ACKNOWLEDGEMENTS}

This study was partly supported by grants NSC 97-2314-B-182A-054-MY2 (HC Kuo) and NSC 98-2314-B-182A-004-MY3 (H R Yu) from the National Science Council of Taiwan; by an excellence for cancer research center grant, Department of Health, Executive Yuan, Taiwan, ROC (NO.DOH99-TD-C-111002), by a grant from Center of Excellence for Environmental Medicine, Kaohsiung Medical University (KMU-EM-99-6-4) and by a grant (NSC 98-2320-B-037 -028 -MY2) from the National Science Council, Taiwan, ROC, these three grants to WC Chang. This work was carried out as a joint project by the institutes to which the authors are affiliated. The institutes had no influence on the collection, analysis and interpretation of the data and on the preparation of the paper.

1 Kawasaki, T. Acute febrile mucocutaneous syndrome with lymphoid involvement with specific desquamation of the fingers and toes in children. Arerugi 16, 178-222 (1967).

2 Wang, C. L., Wu, Y. T., Liu, C. A., Kuo, H. C. \& Yang, K. D. Kawasaki disease: infection, immunity and genetics. Pediatr. Infect. Dis J. 24, 998-1004 (2005).

3 Burns, J. C. \& Glode, M. P. Kawasaki syndrome. Lancet 364, 533-544 (2004).

4 Park, Y. W., Han, J. W., Park, I. S., Kim, C. H., Cha, S. H., Ma, J. S. et al. Kawasaki disease in Korea, 2003-2005. Pediatr. Infect. Dis J. 26, 821-823 (2007).

5 Huang, W. C., Huang, L. M., Chang, I. S., Chang, L. Y., Chiang, B. L., Chen, P. J. et al. Epidemiologic features of Kawasaki disease in Taiwan, 2003-2006. Pediatrics 123, e401-e405 (2009).

6 Nakamura, Y., Yashiro, M., Uehara, R., Oki, I., Kayaba, K., Yanagawa, H. et al. Increasing incidence of Kawasaki disease in Japan: nationwide survey. Pediatr. Int. 50, 287-290 (2008)

7 Kuo, H. C., Liang, C. D., Wang, C. L., Yu, H. R., Hwang, K. P., Yang, K. D. et al. Serum albumin level predicts initial intravenous immunoglobulin treatment failure in Kawasaki disease. Acta. Paediatr. 99, 1578-1583 (2010).

8 Liang, C. D., Kuo, H. C., Yang, K. D., Wang, C. L. \& Ko, S. F. Coronary artery fistula associated with Kawasaki disease. Am. Heart. J. 157, 584-588 (2009).

9 Newburger, J. W., Takahashi, M., Gerber, M. A., Gewitz, M. H., Tani, L. Y., Burns, J. C. et al. Diagnosis, treatment, and long-term management of Kawasaki disease: a statement for health professionals from the Committee on Rheumatic Fever, Endocarditis, and Kawasaki Disease, Council on Cardiovascular Disease in the Young, American Heart Association. Pediatrics 114, 1708-1733 (2004).

10 Kuo, H. C., Wang, C. L., Liang, C. D., Yu, H. R., Huang, C. F., Wang, L. et al. Association of lower eosinophil-related T helper 2 (Th2) cytokines with coronary artery lesions in Kawasaki disease. Pediatr. Allergy. Immunol. 20, 266-272 (2009).

11 Esper, F., Shapiro, E. D., Weibel, C., Ferguson, D., Landry, M. L., Kahn, J. S. et al. Association between a novel human coronavirus and Kawasaki disease. J. Infect. Dis. 191, 499-502 (2005).

12 Chang, L. Y., Chiang, B. L., Kao, C. L., Wu, M. H., Chen, P. J., Berkhout, B. et al. Lack of association between infection with a novel human coronavirus ( $\mathrm{HCoV}$ ), $\mathrm{HCoV}-\mathrm{NH}$, and Kawasaki disease in Taiwan. J. Infect. Dis. 193, 283-286 (2006).

13 Ebihara, T., Endo, R., Ma, X., Ishiguro, N. \& Kikuta, H. Lack of association between New Haven coronavirus and Kawasaki disease. J. Infect. Dis. 192, 351-352 (2005), author reply 353

14 Onouchi, Y., Gunji, T., Burns, J. C., Shimizu, C., Newburger, J. W., Yashiro, M. et al. ITPKC functional polymorphism associated with Kawasaki disease susceptibility and formation of coronary artery aneurysms. Nat. Genet. 40, 35-42 (2008). 
15 Onouchi, Y., Ozaki, K., Buns, J. C., Shimizu, C., Hamada, H., Honda, T. et al. Common variants in CASP3 confer susceptibility to Kawasaki disease. Hum. Mol. Genet. 19, 2898-2906 (2010).

16 Chi, H., Huang, F. Y., Chen, M. R., Chiu, N. C., Lee, H. C., Lin, S. P. et al. ITPKC gene SNP rs28493229 and Kawasaki disease in Taiwanese children. Hum. Mol. Genet. 19, 1147-1151 (2010)

17 Hengartner, M. O. The biochemistry of apoptosis. Nature 407, 770-776 (2000)

18 Nicholson, D. W. \& Thornberry, N. A. Caspases: killer proteases. Trends. Biochem. Sci. 22, 299-306 (1997).

19 Budihardjo, I, Oliver, H., Lutter, M., Luo, X. \& Wang, X. Biochemical pathways of caspase activation during apoptosis. Annu. Rev. Cell. Dev. Biol. 15, 269-290 (1999).

20 Soung, Y. H., Lee, J. W., Kim, S. Y., Park, W. S., Nam, S. W., Lee, J. Y. et al. Somatic mutations of CASP3 gene in human cancers. Hum. Genet. 115, 112-115 (2004).

21 Kurokawa, H., Nishio, K., Fukumoto, H., Tomonari, A., Suzuki, T., Saijo, N. et al. Alteration of caspase-3 (CPP32/Yama/apopain) in wild-type MCF-7, breast cancer cells. Oncol. Rep. 6, 33-37 (1999).

22 Chen, K., Zhao, H., Hu, Z., Wang, L. E., Zhang, W., Sturgis, E. M. et al. CASP3 polymorphisms and risk of squamous cell carcinoma of the head and neck. Clin. Cancer. Res. 14, 6343-6349 (2008).

23 Kuo, H. C., Wang, C. L., Liang, C. D., Yu, H. R., Chen, H. H., Wang, L. et al. Persistent monocytosis after intravenous immunoglobulin therapy correlated with the development of coronary artery lesions in patients with Kawasaki disease. J. Microbiol. Immunol. Infect. 40, 395-400 (2007).

24 Shulman, S. T., De Inocencio, J. \& Hirsch, R. Kawasaki disease. Pediatr. Clin. North Am. 42, 1205-1222 (1995).

25 JCS Joint Working Group. Guidelines for diagnosis and management of cardiovascular sequelae in Kawasaki disease (JCS 2008)-digest version. Circ. J. 74, 1989-2020 (2010).

26 Kuo, H. C., Yang, K. D., Liang, C. D., Bong, C. N., Yu, H. R., Wang, L. et al. The relationship of eosinophilia to intravenous immunoglobulin treatment failure in Kawasaki disease. Pediatr. Allergy. Immunol. 18, 354-359 (2007).

27 Kuo, H. C., Wang, C. L., Wang, L., Yu, H. R. \& Yang, K. D. Patient characteristics and intravenous immunoglobulin product may affect eosinophils in Kawasaki disease. Pediatr. Allergy. Immunol. 19, 184-185 (2008).

28 Yang, K. D., Ou, C. Y., Chang, J. C., Chen, R. F., Liu, C. A., Liang, H. M. et al. Infant frequent wheezing correlated to Clara cell protein 10 (CC10) polymorphism and concentration, but not allergy sensitization, in a perinatal cohort study. J. Allergy. Clin. Immunol. 120, 842-848 (2007).

29 Shimizu, C., Matsubara, T., Onouchi, Y, Jain, S., Sun, S., Nievergelt, C. M. et al. Matrix metalloproteinase haplotypes associated with coronary artery aneurysm formation in patients with Kawasaki disease. J. Hum. Genet. 55, 779-784 (2010).

30 Kariyazono, H., Ohno, T., Khajoee, V., Ihara, K., Kusuhara, K., Kinukawa, N. et al. Association of vascular endothelial growth factor (VEGF) and VEGF receptor gene polymorphisms with coronary artery lesions of Kawasaki disease. Pediatr. Res. 56, 953-959 (2004).

31 Breunis, W. B., Biezeveld, M. H., Geissler, J., Ottenkamp, J., Kuipers, I. M., Lam, J. et al. Vascular endothelial growth factor gene haplotypes in Kawasaki disease. Arthritis. Rheum. 54, 1588-1594 (2006).

32 Huang, F. Y., Chang, T. Y., Chen, M. R., Lee, H. C., Chi, H., Chiu, N. C. et al. Lack of association of the vascular endothelial growth factor gene polymorphisms with Kawasaki disease in Taiwanese children. J. Clin. Immunol. 28, 322-328 (2008).

33 Burns, J. C., Shimizu, C., Shike, H., Newburger, J. W., Sundel, R. P., Baker, A. L. et al. Family-based association analysis implicates IL-4 in susceptibility to Kawasaki disease. Genes. Immun. 6, 438-444 (2005).

34 Huang, F. Y., Chang, T. Y., Chen, M. R., Lee, H. C., Chiu, N. C., Chi, H. et al. The -590 $\mathrm{C} / \mathrm{T}$ and $8375 \mathrm{~A} / \mathrm{G}$ interleukin-4 polymorphisms are not associated with Kawasaki disease in Taiwanese children. Hum. Immunol. 69, 52-57 (2008).

35 Wu, S. F., Chang, J. S., Wan, L., Tsai, C. H. \& Tsai, F. J. Association of IL-1Ra gene polymorphism, but no association of IL-1beta and IL-4 gene polymorphisms, with Kawasaki disease. J. Clin. Lab. Anal. 19, 99-102 (2005).

36 Wu, S. F., Chang, J. S., Peng, C. T., Shi, Y. R. \& Tsai, F. J. Polymorphism of angiotensin-1 converting enzyme gene and Kawasaki disease. Pediatr. Cardiol. 25, 529-533 (2004).

37 Fukazawa, R., Sonobe, T., Hamamoto, K., Hamaoka, K., Sakata, K. Asano, T. et al. Possible synergic effect of angiotensin-I converting enzyme gene insertion/deletion polymorphism and angiotensin-II type-1 receptor $1166 \mathrm{~A} / \mathrm{C}$ gene polymorphism on ischemic heart disease in patients with Kawasaki disease. Pediatr. Res. 56, 597-601 (2004).

38 Lin, M. T., Wang, J. K., Yeh, J. I., Sun, L. C., Chen, P. L., Wu, J. F. et al. Clinical Implication of the C Allele of the ITPKC Gene SNP s28493229 in Kawasaki Disease: Association With Disease Susceptibility and BCG Scar Reactivation. Pediatr. Infect. Dis. J. (2010). 